\title{
Gaming Motivations among American College Students
}

\author{
Yeong $\mathrm{Chi}^{1}$, Marvin Glen Lovett ${ }^{2} \& \mathrm{Orson}_{\mathrm{Chi}^{3}}$ \\ ${ }^{1}$ Department of Natural Sciences, The University of Maryland Eastern Shore, United States \\ ${ }^{2}$ University of Texas-Rio Grande Valley, United States \\ ${ }^{3}$ CHI Analytical Consulting Services, United States \\ Correspondence: Yeong Chi, Department of Natural Sciences, The University of Maryland Eastern Shore, USA. \\ E-mail: ychi@umes.edu
}

Received: February 12, 2016

Accepted: April 30, 2017

Online Published: May 17, 2017

doi:10.5539/ijbm.v12n6p211

URL: https://doi.org/10.5539/ijbm.v12n6p211

\begin{abstract}
The purpose of this study was to examine American college students' motivations related to video games and to identify groups exhibiting common patterns of responses. This study investigated the video gaming motivations of American college students through the adoption of a gaming motivation scale, developed by Lafrenière, et al., which was composed of 18 Likert-typed items. A questionnaire survey, administered to 191 American college students at a public university in South Texas, was employed to collect primary data for this study. The gaming motivations of these participants were examined through factor analysis, which identified four reliable factors. Cluster analysis was then employed to identify three prominent video gaming motivation groups. This research may provide practical marketing implications by proposing effective ways to better understand and target video gaming consumers. Research results may also provide direction for developing successful marketing strategies in the video gaming industry.
\end{abstract}

Keywords: gaming motivation scale, American college students, factor analysis, cluster analysis

\section{Introduction}

The global video gaming industry has seen consumer demand soar due to a number of factors including social networking, technological innovation, and marketing promotions. The growth of the video gaming industry in the United States is reflected by the fact that $42 \%$ of Americans play video games on a regular basis (Gallagher, 2015). Playing video games on a "regular basis" refers to playing three hours or more per week. The average age of American video gamers is 35 years and the majority of American gamers are 18-35 years old, which includes college students. These ages are associated with Millennials and Generation Z cohorts. Born between 1981 and 1995, Millennials include approximately $60,000,000$ consumers in the United States. Generation Z also includes approximately 60,000,000 consumers, born between 1995 and 2010 (Babib \& Harris, 2013).

Understanding the motivations related to video game playing is an essential prerequisite to the continued success of the video gaming industry (Przbylski, et al. 2010; Iacovides, et al. 2011; Wang, et al. 2011; Li, 2012). Video games provide an extraordinary kind of intimacy with machines in interactive and rule-governed microworlds where players enter into a virtual environment of infinite possibilities experiencing altered states of consciousness and becoming absorbed in what is happening onscreen (Turkle, 1984). These virtual environments, which are complex, emergent systems of uncertainty, information and conflict, are governed by the concept of "play" that refers to a range of activities accompanied by a state of pleasure and enjoyment (Iacovides, et al. 2011).

Bartle (1996) provided important insight into how players may differ from one another and he suggested a categorization of four types of video game players: socializers, achievers, killers, and explorers, which are a well-known model of video game player motivations. These motivation-based groups related to video game players need for (1) socializing with others (players use video games as a context to converse with others), (2) achievement within the game (players have specific game-related goals and seek to achieve them), (3) imposition upon others (players use video games to impose distress or help others), and (4) exploration of the game (players attempt to explore as much as they can about the virtual world).

Using a factor analytical approach, Yee (2007) found that motivations for use of Massively-Multiplayer Online 
(MMO) video games were comprised of three main components: (1) achievement (comprised of advancement, mechanics, and competition as subcomponents), (2) sociability (comprised of socializing, relationship, and teamwork as subcomponents), and (3) immersion (comprised of discovery, role-play, customization, and escapism as subcomponents).

A subsequent study conducted by Williams, Yee and Caplan (2008) revealed that the three factors were significant predictors of video game total playing time. In addition, Przbylski, et al. (2010) pointed out that the motives related to playing video games vary but involve four primary motives: power, identity, imagination, and the self. Power motives relate to the conflict and sense of contest experienced during video game play. Identity motives relate to the means of expressing an identity and belonging to a group through the video game play experience. Imagination motives relate to the creative and imaginary environments provided to the video game player. Motives related to the self-relate to entertainment, relaxation and escape provided by the video game experience.

Recently, Lafrenière, et al. (2012) developed a gaming motivation scale, a valid assessment of gaming motivation, based on the framework of self-determination theory and found six three-items distinctive video gaming motivation dimensions representing intrinsic motivation, integrated regulation, identified regulation, introjected regulation, external regulation, and amotivation. Interestingly, all types of motivation related positively, while amotivation negatively to gaming frequency.

Although the video gaming industry is growing significantly, no systematic study has been conducted related to understanding college students from a gaming motive perspective and specifically on profiling these groups of college students using the gaming motivation scale approach. With updated testing of the well-developed conceptual framework of the gaming motivation scale among college students, this research may contribute to existing decision-making literature by either providing more evidence of the validity and robustness of this framework or by providing suggestions for adaptation in applying this framework to understand college student groups across different backgrounds and cultures.

Also, this research may add more to the existing literature on the dynamically changing behaviors of college students. This research may provide practical marketing implications for video game education by proposing effective ways to understand and target these consumers. Research results may also provide direction for developing marketing strategies, which target American consumers, especially American college students.

\section{Method}

A questionnaire survey was administered to collect primary data administered to 191 college students in a public university in South Texas during the fall semester of 2013. The gaming motivation scale, which was designed to assess intrinsic motivation, integrated, identified, introjected, and external regulation, as well as amotivation (Lafrenière, et al. 2012), was composed of 18 Likert-scaled items scored from 1 (strongly disagree) to 5 (strongly agree). Using a relatively homogeneous group such as college students minimizes random error that might occur by using a heterogeneous sample such as the general public (Calder, et al. 1981). In this study, non-probability sampling technique was used. Although the results of the studies conducted on such samples cannot be generalized, the common aim of these studies were to test the transferability of the inventory to different environments and non-probability sampling was found to be appropriate.

The analysis examined the psychometric properties of the 18-item gaming motivation scale (Table 1). First, the dimensionality of the 18-item gaming motivation scale was assessed by examining the factor solution (Gerbing \& Anderson, 1988). Specifically, the amount of variance explained by the extracted factors (i.e., their eigenvalues) was noted. In addition, item-factor correlations (i.e., factor loadings) and other indices of model adequacy were examined. A principal component analysis was used to determine the factors identified. Second, a cluster analysis of respondents was conducted using a two-stage process to identify respondent groups exhibiting common patterns of responses.

Table 1. Descriptive Analysis of Gaming Motivations

\begin{tabular}{lccc}
\hline Item & Mean & S.D. & Extraction \\
\hline Because it is stimulating to play & 3.86 & 1.10 & 0.70 \\
For the pleasure of trying/experiencing new game options & 3.92 & 1.03 & 0.70 \\
For the feeling of efficacy I experience when I play & 3.27 & 1.15 & 0.69 \\
Because it is an extension of me & 2.66 & 1.31 & 0.68 \\
Because it is an integral part of my life & 2.35 & 1.28 & 0.78 \\
\hline
\end{tabular}




\begin{tabular}{llll}
\hline Because it is aligned with my personal values & 2.26 & 1.21 & 0.78 \\
Because it is a good way to develop important aspects of myself & 2.60 & 1.31 & 0.68 \\
Because it is a good way to develop social and intellectual abilities that are useful to me & 2.91 & 1.38 & 0.59 \\
Because it has personal significance to me & 2.63 & 1.33 & 0.67 \\
Because I feel that I must play regularly & 2.23 & 1.21 & 0.69 \\
Because I must play to feel good about myself & 1.96 & 1.20 & 0.78 \\
Because otherwise I would feel bad about myself & 1.69 & 1.09 & 0.74 \\
To acquire powerful and rare items and virtual currency or to unlock hidden/restricted elements of & 2.91 & 1.46 & 0.75 \\
the game & 3.22 & 1.42 & 0.69 \\
For the prestige of being a good player & 3.04 & 1.38 & 0.83 \\
To gain in-game awards and trophies or character/avatar's levels and experiences points & 2.52 & 1.28 & 0.80 \\
It is not clear anymore; I sometimes ask myself if it is good for me & 2.35 & 1.27 & 0.81 \\
I used to have good reasons, but now I am asking myself if I should continue & 2.77 & 1.66 & 0.78 \\
Honestly, I don't know; I have the impression that I'm wasting my time &
\end{tabular}

\section{Results}

\subsection{Factor Analysis}

The original 18 -item gaming motivation scale was factor analyzed with varimax rotation, providing a clearer separation of the factors. The factor loading of the four resulting factors are shown in Table 2. The KMO measure of sampling adequacy was 0.885 , which met the fundamental requirements for factor analysis. The Bartlett's test of Sphericity showed that nonzero correlations exist at the significance level of 0.001 (Table 2).

The Cronbach's alpha is the most widely used measure of reliability, which is an assessment of the degree of consistency between multiple measurements of a variable. The generally agreed upon lower limit for the Cronbach's alpha is 0.70 , although it may decrease to 0.60 in exploratory research (Hair, Jr., et al. 1998). The internal consistency coefficient score of the 18-item gaming motivation scale showed the Cronbach's alpha of 0.910 was acceptable. Each of these three factors had a satisfactory Cronbach's alpha of $0.928,0.816,0.853$, and 0.848 , respectively, which explained a cumulative 73.04 percent of the variance in statement response (Table 2).

Table 2. Factor analysis of gaming motivations

\begin{tabular}{|c|c|c|c|c|}
\hline Item & $\begin{array}{c}\text { Overall } \\
\text { Regulation }\end{array}$ & $\begin{array}{c}\text { Intrinsic } \\
\text { Motivation }\end{array}$ & $\begin{array}{c}\text { External } \\
\text { Regulation }\end{array}$ & Amotivation \\
\hline Because it is stimulating to play & & 0.798 & & \\
\hline For the pleasure of trying/experiencing new game options & & 0.733 & & \\
\hline For the feeling of efficacy I experience when I play & & 0.735 & & \\
\hline Because it is an extension of me & 0.650 & & & \\
\hline Because it is an integral part of my life & 0.800 & & & \\
\hline Because it is aligned with my personal values & 0.794 & & & \\
\hline Because it is a good way to develop important aspects of myself & 0.679 & & & \\
\hline $\begin{array}{l}\text { Because it is a good way to develop social and intellectual abilities } \\
\text { that are useful to me }\end{array}$ & 0.579 & & & \\
\hline Because it has personal significance to me & 0.697 & & & \\
\hline Because I feel that I must play regularly & 0.752 & & & \\
\hline Because I must play to feel good about myself & 0.813 & & & \\
\hline Because otherwise I would feel bad about myself & 0.804 & & & \\
\hline $\begin{array}{l}\text { To acquire powerful and rare items and virtual currency or to unlock } \\
\text { hidden/restricted elements of the game }\end{array}$ & & & 0.798 & \\
\hline For the prestige of being a good player & & & 0.731 & \\
\hline $\begin{array}{l}\text { To gain in-game awards and trophies or character/avatar's levels and } \\
\text { experiences points }\end{array}$ & & & 0.871 & \\
\hline It is not clear anymore; I sometimes ask myself if it is good for me & & & & 0.859 \\
\hline $\begin{array}{l}\text { I used to have good reasons, but now I am asking myself if I should } \\
\text { continue }\end{array}$ & & & & 0.879 \\
\hline $\begin{array}{l}\text { Honestly, I don't know; I have the impression that I'm wasting my } \\
\text { time }\end{array}$ & & & & 0.871 \\
\hline
\end{tabular}




$\begin{array}{lccc}\text { Eigenvalue } & 5.248 & 2.986 & 2.522 \\ \text { \% of variance } & 29.156 & 15.590 & 2.390 \\ \text { Cumulative \% } & 29.156 & 45.946 & 13.013 \\ \text { Cronbach's Alpha Coefficient } & 0.928 & 0.816 & 0.759 \\ \text { Cronbach's Alpha Coefficient for All Statements } & & 0.910 \\ \text { KMO Measure of Sampling Adequacy } & & 0.885 \\ \text { Bartlet's test of Sphericity: Approx. } \chi^{2}=2404.100 ; d f=153 ; \text { Sig. }=0.000 & & \end{array}$

As the result of the exploratory factor analysis, four factors were identified. Each factor was named by examining the content of the variable making the greatest contribution to each of the dimensions. An initial interpretation of these factors suggested that Factor 1 named "Overall Regulation" factor comprising nine items (structure coefficients ranging from 0.813 to 0.579 ) and explained 29.156 percent of the variance with an eigenvalue of 5.248. Factor 2 emphasized "Intrinsic Motivation" factor comprising three items (structure coefficients ranging from 0.798 to 0.733 ) and explained 15.590 percent of the variance with an eigenvalue of 2.986. Factor 3 focuses on "External Regulation" factor comprising three items (structure coefficients ranging from 0.871 to 0.731 ) and explained 14.013 percent of the variance with an eigenvalue of 2.522. Factor 4 titled "Amotivation" factor comprising three items (structure coefficients ranging from 0.879 to 0.859 ) and explained 13.277 percent of the variance with an eigenvalue of 2.390 .

\subsection{Cluster Analysis}

Cluster analysis techniques assign objects to groups so that there is as much similarity within groups, and difference between groups, as possible (Churchill, Jr. \& Iacobucci, 2005). Cluster analysis was applied as a two-stage process to the saved factor scores. In the first stage, Ward's hierarchical clustering method was employed to provide an indication of the appropriate number of clusters. In the second stage, the K-means clustering method was used to identify a solution with the specified number of clusters. Consequently, a three-cluster solution was agreed upon. The clusters were labeled as "Active", "Passive" and "Anxious" gaming player groups (Table 3).

"Active" gaming player cluster: this was the smallest group comprising of approximately 22.5 percent of the respondents, this group was named after the positively strong association with "Intrinsic Motivation" and "Overall Regulation" factors, but negatively identified with "Amotivation" and "External Regulation" factors. "Passive" gaming player cluster: this was the largest group with 40.8 percent of the respondents, this group named because of the high factor score associated with "Overall Regulation" factor among these respondents. This group however negatively identified with all four factors. "Anxious" gaming player cluster: comprised of approximately 36.7 percent of the respondents. These respondents were positively and strongly connected with "Amotivation" and "Overall Regulation" factors, but negatively identified with "Intrinsic Motivation" factors.

Table 3. Mean factor scores for gaming player clusters

\begin{tabular}{lccc}
\hline Factor / Cluster & Active Gaming Player & Passive Gaming Player & Anxious Gaming Player \\
\hline Overall Regulation & 0.464 & -0.810 & 0.618 \\
Intrinsic Motivation & 0.890 & -0.473 & -0.020 \\
External Regulation & -0.031 & -0.132 & 0.167 \\
Amotivation & -0.973 & -0.162 & 0.778 \\
$\mathrm{~N}=191$ & 43 & 78 & 70 \\
Percentage & 22.5 & 40.8 & 36.7 \\
\hline
\end{tabular}

Results of the cluster analysis were tested for accuracy using the multiple discriminant analysis employed as a useful complement to cluster analysis, which is used primarily to predict membership in two or more mutually exclusive groups. In this case, the null hypothesis of equal population covariance matrices was rejected at $5 \%$ level of significance (the Box's $\mathrm{M}=109.981 ; F=5.316 ; p=0.000$ ), and the Wilk's Lambda scores were 0.160 $\left(\chi^{2}=341.938 ; d f=8 ; p=0.000\right)$ and $0.446\left(\chi^{2}=150.735 ; d f=3 ; p=0.000\right)$ for both discriminant functions, respectively, indicating that group means were significantly different. The canonical correlation results were both above 0.7 , supporting the existence of a strong relationship between the discriminant score and the cluster membership (Table 4). 
Table 4. Canonical correlation of discriminant functions

\begin{tabular}{cccc}
\hline Function & Eigenvalue & \% of Variance & Canonical Correlation \\
\hline 1 & $1.788^{*}$ & 59 & 0.801 \\
2 & $1.244^{*}$ & 41 & 0.745 \\
\hline
\end{tabular}

* First 2 canonical discriminant functions were used in the analysis.

Two discriminant functions were formulated (Table 5). The first function was a function for discriminating between cluster 1 and cluster 2 and 3 combined, and the second function for discriminating between cluster 2 and cluster 3 , respectively. Though mathematically different, each discriminant function was a dimension, which differentiates a case into categories of the dependent variable (cluster1, cluster 2 or cluster 3) based on its values on the independent variables. The first function was the most powerful differentiating dimension, but the second function may also represent additional significant dimensions of differentiation.

Table 5. Standardized canonical discriminant function coefficient

\begin{tabular}{lcc}
\hline & Function 1 & Function 2 \\
\hline Overall Regulation & 1.037 & 0.068 \\
Intrinsic Motivation & 0.691 & -0.596 \\
External Regulation & 0.230 & 0.144 \\
Amotivation & 0.227 & 0.976 \\
\hline
\end{tabular}

\subsection{Statistical Test}

Using the Chi-square test, there were significant differences among gaming player groups for all 18 gaming motivations at a 0.01 level. Responses to "Because it is an integral part of my life", for example, varied significantly among clusters $\left(\chi^{2}=113.722, d f=8, p=0.000\right)$. While about $95 \%$ of "Passive" gaming players said that "Because it is an integral part of my life" was "strongly disagree" or "moderate disagree", while $46.5 \%$ of "Active" gaming players and $25.7 \%$ of "Anxious" gaming players rating being as "moderate agree" or "strongly agree" to the same statement (Table 6).

In terms of the statement "For the prestige of being a good player", about $70 \%$ of "Active" gaming players and $61 \%$ of "Anxious" gaming players said that "For the prestige of being a good player" were "strongly agree" or "moderate agree", but less than $54 \%$ of "Passive" gaming players rating being as "moderate disagree" or "strongly disagree" (Table 6).

Table 6. Percentage of item response of gaming player clusters

\begin{tabular}{|c|c|c|c|c|c|c|}
\hline \multirow{2}{*}{$\begin{array}{l}\text { Group } \\
\text { Scale }\end{array}$} & \multicolumn{2}{|c|}{$\begin{array}{l}\text { Active Gaming } \\
\text { Player }\end{array}$} & \multicolumn{2}{|c|}{$\begin{array}{l}\text { Passive Gaming } \\
\text { Player }\end{array}$} & \multicolumn{2}{|c|}{$\begin{array}{l}\text { Anxious Gaming } \\
\text { Player }\end{array}$} \\
\hline & $1 \& 2$ & $4 \& 5$ & $1 \& 2$ & $4 \& 5$ & $1 \& 2$ & $4 \& 5$ \\
\hline Because it is stimulating to play & $0.0 \%$ & $93.0 \%$ & $24.2 \%$ & $57.7 \%$ & $2.9 \%$ & $74.2 \%$ \\
\hline For the pleasure of trying/experiencing new game options & $2.3 \%$ & $97.6 \%$ & $20.6 \%$ & $60.2 \%$ & $2.9 \%$ & $77.2 \%$ \\
\hline For the feeling of efficacy I experience when I play & $2.3 \%$ & $76.7 \%$ & $42.3 \%$ & $19.2 \%$ & $10.0 \%$ & $51.5 \%$ \\
\hline Because it is an extension of me & $18.7 \%$ & $53.5 \%$ & $73.4 \%$ & $2.6 \%$ & $21.4 \%$ & $38.6 \%$ \\
\hline Because it is an integral part of my life & $25.6 \%$ & $46.5 \%$ & $94.9 \%$ & $0.0 \%$ & $37.1 \%$ & $25.7 \%$ \\
\hline Because it is aligned with my personal values & $30.3 \%$ & $41.8 \%$ & $96.4 \%$ & $0.0 \%$ & $41.4 \%$ & $24.3 \%$ \\
\hline Because it is a good way to develop important aspects of myself & $23.2 \%$ & $48.8 \%$ & $87.2 \%$ & $1.3 \%$ & $21.5 \%$ & $38.6 \%$ \\
\hline $\begin{array}{l}\text { Because it is a good way to develop social and intellectual } \\
\text { abilities that are useful to me }\end{array}$ & $13.9 \%$ & $76.7 \%$ & $73.0 \%$ & $11.5 \%$ & $17.2 \%$ & $54.2 \%$ \\
\hline Because it has personal significance to me & $20.9 \%$ & $65.1 \%$ & $84.6 \%$ & $6.4 \%$ & $22.8 \%$ & $35.7 \%$ \\
\hline Because I feel that I must play regularly & $46.5 \%$ & $30.2 \%$ & $91.0 \%$ & $2.6 \%$ & $37.1 \%$ & $27.2 \%$ \\
\hline Because I must play to feel good about myself & $69.8 \%$ & $18.6 \%$ & $96.2 \%$ & $2.6 \%$ & $34.2 \%$ & $21.4 \%$ \\
\hline Because otherwise I would feel bad about myself & $88.4 \%$ & $4.7 \%$ & $98.7 \%$ & $0.0 \%$ & $51.4 \%$ & $17.2 \%$ \\
\hline $\begin{array}{l}\text { To acquire powerful and rare items and virtual currency or to } \\
\text { unlock hidden / restricted elements of the game }\end{array}$ & $34.9 \%$ & $60.5 \%$ & $58.9 \%$ & $25.6 \%$ & $20.0 \%$ & $42.9 \%$ \\
\hline For the prestige of being a good player & $21.0 \%$ & $69.8 \%$ & $53.8 \%$ & $38.5 \%$ & $12.9 \%$ & $61.4 \%$ \\
\hline
\end{tabular}




\begin{tabular}{|c|c|c|c|c|c|c|}
\hline $\begin{array}{l}\text { To gain in-game awards and trophies or character/avatar's levels } \\
\text { and experiences points }\end{array}$ & $30.3 \%$ & $58.1 \%$ & $50.0 \%$ & $34.6 \%$ & $17.2 \%$ & $48.5 \%$ \\
\hline $\begin{array}{l}\text { It is not clear anymore; I sometimes ask myself if it is good for } \\
\text { me }\end{array}$ & $79.1 \%$ & $4.7 \%$ & $61.6 \%$ & $9.0 \%$ & $9.6 \%$ & $51.4 \%$ \\
\hline $\begin{array}{l}\text { I used to have good reasons, but now I am asking myself if I } \\
\text { should continue }\end{array}$ & $93.0 \%$ & $0.0 \%$ & $66.7 \%$ & $7.7 \%$ & $11.4 \%$ & $44.3 \%$ \\
\hline $\begin{array}{l}\text { Honestly, I don't know; I have the impression that I'm wasting } \\
\text { my time }\end{array}$ & $88.4 \%$ & $7.0 \%$ & $44.9 \%$ & $30.8 \%$ & $14.3 \%$ & $50.0 \%$ \\
\hline
\end{tabular}

$($ Strongly disagree $=1$, Moderate disagree $=2$, Undecided $=3$, Moderate agree $=4$, strongly agree $=5)$

For most of the "Intrinsic Motivation" factor items, the "Active" gaming player cluster contained a larger portion of "moderate agree" or "strongly agree" responses than the "Passive" and "Anxious" gaming player clusters. Similarly, for most of the "Amotivation" factor items, the "Anxious" gaming player cluster contained a larger portion of "moderate agree" or "strongly agree" responses than the "Active" and "Passive" gaming player clusters (Table 6).

Using the one-way ANOVA, the results showed that significant differences among cluster composition were found with the four factors identified (Table 7). Those of significant differences were "Overall Regulation" $(F(2$, $188)=79.732, p=0.000)$, “Intrinsic Motivation" $(F(2,188)=34.960, p=0.000)$, and “Amotivation" $(F(2,188)$ $=76.286, p=0.000)$, but insignificant differences with "External Regulation" $(F(2,188)=1.686, p=0.188)$.

Table 7. Cluster differences in the identified gaming motivation factors

\begin{tabular}{lccc}
\hline Factor & & $d f$ & $F$ \\
\hline Overall Regulation & Between Groups & 2 & 79.732 \\
& Within Groups & 188 & 0.000 \\
Intrinsic Motivation & Between Groups & 2 & 34.960 \\
& Within Groups & 188 & 0.000 \\
External Regulation & Between Groups & 2 & 1.686 \\
Amotivation & Within Groups & 188 & 76.286 \\
& Between Groups & 2 & 0.188 \\
\end{tabular}

Using the Chi-square test, the identified three groups demonstrated significant differences in average hours playing game in a typical day $\left(\chi^{2}=26.293 ; d f=10 ; p=0.003\right)$ (Table 8$)$. About $77 \%$ of "Passive" gaming players played less than an hour, but $7 \%$ of "Active" gaming players played five to six hours much more than "Passive" and "Anxious" gaming players in a typical day. Still 10\% of "Anxious" gaming players played the game three to four hours in a typical day.

Table 8. Cluster differences in average hours playing game in a typical day

\begin{tabular}{|c|c|c|c|}
\hline Hours & Active Game Player & Passive Game Player & Anxious Game Player \\
\hline Less than 1 hour & $37.2 \%$ & $76.9 \%$ & $57.1 \%$ \\
\hline $1-2$ hours & $34.9 \%$ & $11.5 \%$ & $30.0 \%$ \\
\hline $3-4$ hours & $18.6 \%$ & $7.7 \%$ & $10.0 \%$ \\
\hline $5-6$ hours & $7.0 \%$ & $1.3 \%$ & $0.0 \%$ \\
\hline $7-8$ hours & $2.3 \%$ & $1.3 \%$ & $1.4 \%$ \\
\hline More than 8 hours & $0.0 \%$ & $1.3 \%$ & $1.4 \%$ \\
\hline
\end{tabular}

\section{Discussion and Conclusion}

Based on a survey administered to 191 American college students, gaming motivations were investigated through the use of a gaming motivation scale, which provides an effective way to segment different video gaming motivation groups. Factor analysis was employed which identified four reliable factors. Lastly, cluster analysis then identified three prominent video gaming motivation groups. This study, using market segmentation approach, may provide further understanding of video game player behavior and to provide opportunities for 
gaming vendors to increase market share.

This market segmentation approach was useful in identifying multiple behaviors of American college students related to video gaming. For example, the significant role of motives related to "Overall Regulation" demonstrates the high degree of importance, which video games play within the lives of American college students. This high degree of importance provides the opportunity for video gaming providers to establish strong brand loyalty among American college students. However, due to the strong influence of "Intrinsic Motivation", the expectations of continued improvements, upgrades and new game options among American college students must be continually anticipated and met. Millennials, for example, are 2.5 times more likely to adopt new technology early and less likely to try a new technology, which is more than one year old (Fromm \& Garton, 2013).

Therefore, frequent upgrades provide video gaming providers with further marketing opportunities and are regularly expected among American college students. Although "External Regulation" was found to be somewhat less influential, the use of external rewards should not be overlooked. While Millennials have been associated with less interest in participation in consumer loyalty programs, when a significant reward is offered, their interest increases. In fact, those Millennials, which do participate in consumer loyalty programs, are 50 percent more likely to promote the programs to others utilizing social media (Fromm \& Garton, 2013).

Although this study addresses American college students, other generational cohorts may be of interest as it is now common for older consumers to adopt and exhibit similar behaviors and traits of younger consumers. Many older consumers are assimilating into Millennial culture and adopting Millennial characteristics to maintain a feeling of relevance. Furthermore, the younger the consumer is, the more likely they will be engaged in new technology, including video games. (Fromm \& Garton, 2013).

This study showed that approximately $19 \%$ of "Active" gaming players played three to four hours, and about $9 \%$ played more than five hours in a typical day. About $77 \%$ of "Passive" gaming players played less than an hour, and more than $11 \%$ played one to two hours in a typical day. For the "Anxious" gaming players, $30 \%$ of these gaming players played one to two hours, and $10 \%$ played three to four hours in a typical day. Lacking certain types of personality traits information, further psychometric evaluations related to the gaming motivations in this study have not been conducted. Motivations can be tracked by certain types of personality traits. Furthermore, certain motivations can be used to predict the genre preference for video gaming and the amount of time spent playing video games.

This research resulted in the segmentation of the college students into different video gaming motivation groups. A limitation of this research is related to the sample framework, a homogenous group of university students with nearly the same age range. For further research, it will be necessary to evaluate other samples including multiple demographic variables to extend the ability to generalize the results.

This research may provide insight into gaming motivations of American college students, further investigations are essential. For example, further segmenting of markets to understand the video gaming players' characteristics based on motivations is important for success within the video gaming industry. Marketing managers may use the findings when developing effective and creative message strategies to attract and retain more video gaming fans.

\section{References}

Babin, B. J., \& Harris, E. G. (2013). Consumer behavior (5th ed.). Mason, OH: Thomson/South-Western.

Bartle, R. A. (1996). Hearts, clubs, diamonds, spades: players who suit MUDS. Retrieved on August 2016 from http://www.mud.co.uk/richard/hcds.htm\#1

Calder, B. J., Phillips, L. W., \& Tybout, A. M. (1981). Designing research for application. Journal of Consumer Research, 8, 197-207. https://doi.org/10.1086/208856

Churchill, G. A. Jr., \& Iacobucci, D. (2005). Marketing research: methodological foundations (9th ed.). Mason, $\mathrm{OH}$ : Thomson/South-Western.

Fromm, J., \& Garton, C. (2013). Marketing to Millennials: reach the largest and most influential generation of consumers ever. New York: Barkley, Inc.

Gallagher, M. D. (2015). Essential facts about the computer and video game industry. Entertainment Software Association.

Gerbing, D. W., \& Anderson, J. C. (1988). An updated paradigm for scale development incorporating unidimensionality and its assessment. Journal of Marketing Research, 25, 186-192. Retrieved on August 
2016 from http://rhowell.ba.ttu.edu/gerbinganderson.pdf

Hair, J. F. Jr., Anderson, R. E., Tatham, R. L., \& Black, W. C. (1998). Multivariate data analysis (5th ed.). Upper Saddle River, NJ: Prentice Hall.

Iacovides, I. et al. (2011). Motivation, engagement and learning through digital games. International Journal of Virtue and personal Learning Environments, 2(2), 1-16. https://doi.org/10.4018/jvple.2011040101

Lafrenière, M. K., Verner-Filion, J., \& Vallerand, R. J. (2012). Development and validation of the gaming motivation scale (GAMS). Personality and Individual Differences, 53, 827-831. https://doi.org/10.1016/j.paid.2012.06.013

Li, Z. (2012). Motivation of virtual goods transactions based on the theory of gaming motivations. Journal of Theoretical and Applied Information Technology, 43(2), 254-260. Retrieved on August 2016 from http://www.jatit.org/volumes/Vol43No2/15Vo143No2.pdf

Przybylski, A. K., Rigby, C. S., \& Ryan, R. M. (2010). A motivational model of video game engagement. Review of General Psychology, 14(2), 154-166. http://dx.doi.org/10.1037/a0019440

Turkle, S. (1984). The second self: computers and the human spirit. New York: Simon \& Schuster

Wang, C. K. J., Liu, W. C., Chye, S., \& Chatzisarantis, N. L. D. (2011). Understanding motivation in internet gaming among Singaporean youth: the role of passion. Computers in Human Behavior, 27, 1179-1184. http://dx.doi.org/10.1016/j.chb.2010.12.012

Williams, D., Yee, N., \& Caplan, S. E. (2008). Who plays, how much, and why? Debunking the stereotypical gamer profile. Journal of Computer-Mediated Communication, 13, 993-1018. http://dx.doi.org/10.1111/j.1083-6101.2008.00428.x

Yee, N. (2007). Motivations of play in online games. Journal of CyberPsychology and Behavior, 9, 772-775. http://dx.doi.org/10.1089/cpb.2006.9.772

\section{Copyrights}

Copyright for this article is retained by the author(s), with first publication rights granted to the journal.

This is an open-access article distributed under the terms and conditions of the Creative Commons Attribution license (http://creativecommons.org/licenses/by/4.0/). 